\title{
TRITIUM DETERMINATION FROM WINE SAMPLES USING LIQUID SCINTILLATION COUNTING
}

\author{
Irina Vagner*, Carmen Varlam, Diana Costinel
}

National Research and Development Institute for Cryogenics and Isotopic Technologies - ICSI Rm. Valcea, 4 Uzinei Street, P.O. Box Râureni 7, 240050, Rm. Valcea, Romania

\begin{abstract}
:
Tritium measurement from aqueous fraction of the wines of known vineyard can be a useful tool in reconstruction of the tritium activity in different areas and makes possible to date the time of the harvest of the grapes. The goal of this study was to develop a suitable method for purification of the aqueous phase from the wine samples, obtained from different type of wines, in order to determine tritium activity concentration using liquid scintillation counting. In this work the influence of the purification method applied to the aqueous samples resulted from wine distillation was assessed by deuterium and tritium measurements, content of organic carbon, $\mathrm{pH}$ and conductivity. The most reliable purification method used for wine aqueous fractions, according with the results obtained for $\mathrm{pH}$, and total organic carbon content is chemical treatment followed by lyophilization.
\end{abstract}

\section{Article info:}

Received 07 December 2020

Received in revised form

26 February 2021

Accepted 05 March 2021

Available online 16 April 2021

\section{Keywords:}

Tritium measurement, liquid

scintillation counting, wine

The influence of How to cite: Vagner, I., Varlam, C., Costinel, D. (2021). Tritium determination from wine samples using liquid scintillation counting. Smart Energy and Sustainable Environment, 24(1), 21-28, 2021, https://doi.org/10.46390/j.smensuen.24121.434.

\section{INTRODUCTION}

Tritium is produced naturally in the upper atmosphere as a result of cosmic ray induced spallation and particle interaction with atmospheric nitrogen and oxygen (Libby, 1946; Geyh and Schleicher 1990). Tritium is oxidized to water, forming HTO, which enters the hydrological cycle. Anthropogenic tritium comes mainly from activities associated with nuclear fuel production, research involving radionuclides, or nuclear reactors.

Tritium measurement from aqueous fraction of the wines of known vintage can be a useful tool in reconstruction of the tritium activity in certain areas (Takahashi et. al., 1969; Kozak and Biro, 1984; Krajcar-Bronic et. al., 1998), which together with ${ }^{14} \mathrm{C}$ activity makes possible to date the time of the harvest of the wine (Schonhofer, 1997). Also the evaluation of the aqueous component of the wine or other alcoholic beverages (Kimura et. 
al., 1998; LLNL, 2016; Baglan et. al., 2015) represents an important part in the process of dose calculation and can provide information about the presence and movement of tritium release to the environment. It was shown (Roether, 1967; Cotarlea et. al., 1998) that tritium content in wine samples is not determined exclusively by water taken up by the roots, but is also influenced to a large extent by direct exchange with atmospheric moisture. Thus, wine is a sample partly of atmospheric moisture at ground level, partly of soil moisture, integrated over a period around three weeks before vintage, assuming that the wine samples were prepared without water addition.

There are studies which demonstrate that tritium activity from the free water of the vegetation samples usually reflects the tritium from the environment while tritium from the organic fraction is usually higher that the regional ambient HTO (Masakazu Ota et. al, 2017; Kimura et. al., 1998). This fact conducted to the conclusion that measurement of tritium activity from aqueous fraction is an important issue, not only for environmental monitoring (LLNL, 2016), but also to determine the tritium level in the environment with the purpose of using in hydrological studies (Kozak and Biro, 1984; Roether, 1967; Takahashi et. al., 1969) or in meteorological studies and dating (Kaufman and Libby, 1954). Tritium measurement from aqueous fraction of the wines of known vintage can be a useful tool in reconstruction of the tritium activity in certain areas (Takahashi et. al., 1969; Kozak and Biro, 1984; Krajcar-Bronic et. al., 1998), which together with ${ }^{14} \mathrm{C}$ activity makes possible to date the time of the harvest of the wine (Schonhofer, 1997). Also, the evaluation of the aqueous component of the wine or other alcoholic beverages (Kimura et. al., 1998; LLNL, 2016) represents an important part in the process of dose calculation and can provide information about the presence and movement of tritium release to the environment.

The main step in measurement of tritium in aqueous fraction of the wines using liquid scintillation counting (LSC) is the removal of all organic compounds from the sample to be measured, giving the fact that any impurity can cause chemiluminescence, color quenching or other interferences to LSC measurement (Varlam et. al., 2015).

The goal of this study was to develop a suitable method for purification of aqueous phase of the wine samples, obtained from different type of wines, in order to determine tritium activity concentration using LSC. Most of methods used for removal of the interferences from aqueous fraction of the wine implied neutralization of the acidic components and oxidation of the organic compounds, using potassium permanganate (Scherer et. al., 2009), sodium peroxide (Kozar and Biro, 1984) or both reagents (Kimura et. al., 1998). Regarding the aqueous phase processing, the methods generally applied were different chemical treatments and distillation (Fischer et. al., 1980; Kozar and Biro, 1984; Scherer et. al., 2009) or multiple distillations with chemical treatment, until a water sample measurable by LSC was obtained (Kimura et. al., 1998).

In this study we assessed, using deuterium measurements, tritium measurements, content of organic carbon, and $\mathrm{pH}$ and conductivity, the influence of the purification method applied over the aqueous samples resulted from wine distillation, in order to determine tritium concentration from aqueous phase of wines using liquid scintillation counting. In this study we used three wine samples, one sample of red wine (VR) and two samples of white wine (VA1 and VA2).

\section{EXPERIMENTAL}

\subsection{Initial wine sample preparation}

In order to separate the aqueous phase of the wine samples, a fractional distillation was performed. Three wine samples from unknown locations or origin, one red wine 
sample, and two white wine samples, were prepared. These were prepared using an automatic distillation control system (ADCS), with 11 Cadiot columns.

After fractional distillation of the wine samples, the aqueous fractions resulted had a high organic content, and the initial wine pigmentation. For this reason, four purification methods were performed, in order to eliminate all the impurities which might interfere with LSC tritium measurement (Figure 1) and, to preserve in the same time hydrogen isotopic content.

\subsection{Description of the purification methods}

In our study we elaborated and tested four methods for purification of the aqueous fraction from wines, as follows and also shown in Figure 1.

First method (M1) implied distillation with chemical treatment, using $\mathrm{Na}_{2} \mathrm{O}_{2}$ and $\mathrm{KMnO}_{4}$, followed by simple distillation.

Second method (M2) implied chemical treatment using $\mathrm{Na}_{2} \mathrm{O}_{2}$ and $\mathrm{KMnO}_{4}$, followed by lyophilization.

Third method (M3) implied mixing the aqueous fraction separated from wine with granulated natural zeolite (clinoptilolite zeolitic tuff), until $\mathrm{pH}$ was around 7 , followed by lyophilisation. This type of material can be used for neutralization of the acidity from sample and also for removal of the impurities, having a good potential in obtaining a suitable sample for LSC tritium measurements.

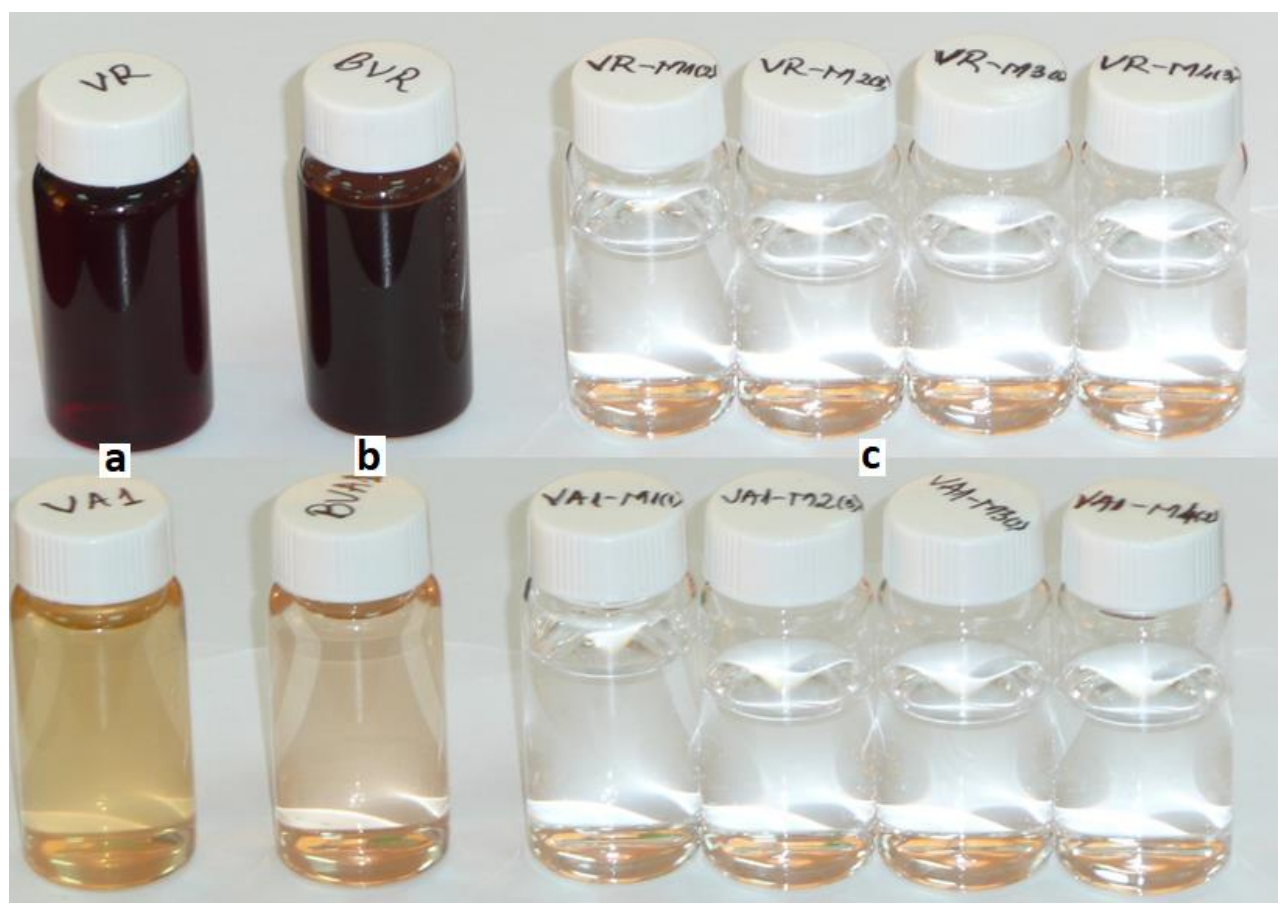

Figure 1. The initial red and white wine samples (a), wine aqueous fractions from red and white wines (b), and purified aqueous fractions, using the mentioned purified methods

The fourth method (M4) implied lyophilisation, without any other prior treatment. This method is the method currently applied in our laboratory for $\delta^{2} \mathrm{H}$ measurement. Charaterisation of the aqueous fractions, initial and purified ones, was done using $\mathrm{pH}$ measurements, electrical conductivity and total organic carbon (TOC) content of the water samples obtained. 


\subsection{Measurement of $\delta^{2} H$}

In order to estimate isotopic fractionation during purification, deuterium isotopic ratio measurements were performed, for each of the aqueous fractions rezulted after applying purification methods described above. The deuterium was determined using GasBench II isotopic equilibration module coupled to Delta V Plus (Thermo Scientific) continuous flow isotope ratio mass spectrometer (CF-IRMS). The experimental conditions for determining the isotopic composition were:

- sample size: $200 \mu \mathrm{l}$;

- $\mathrm{H}_{2} / \mathrm{He}$ equilibration gas: $2 \%$;

- equilibration: minim 60 minutes at $25^{\circ} \mathrm{C}$;

- Reference materials (Iso-Analytical UK):

$$
\begin{aligned}
& \text { IA-R052- } \delta^{2} \mathrm{H}_{\text {VSMOW }}(\% \text { o })=-157.12 \pm 1.35 \\
& \text { IA-R053- } \delta^{2} \mathrm{H}_{\text {VSMOW }}(\%)=-61.97 \pm 2.10 \\
& \text { IA-R063- } \delta^{2} \mathrm{H}_{\text {VSMOW }}(\%)=11.26 \pm 1.34
\end{aligned}
$$

The results have been measured and calculated as deviations versus standards in the $\delta \%$ notation:

$$
\delta * \mathrm{X} / \mathrm{X}(\% \mathrm{o})=\left(\frac{\left({ }^{*} X / X\right)_{\text {sample }}}{\left({ }^{*} \mathrm{X} / \mathrm{X}\right)_{\text {stan dard }}}-1\right) x 1000
$$

The ${ }^{2} \mathrm{H} /{ }^{1} \mathrm{H}$ ratios were measured as $\delta^{2} \mathrm{H}$ relative to the Vienna Standard Mean Ocean Water 2 (VSMOW2) (IAEA, 2017). The conversion from $\delta^{2} \mathrm{H}$ to ${ }^{2} \mathrm{H}$ concentration in ppm was calculated using the formula:

$$
{ }^{2} \mathrm{H}[\mathrm{ppm}]=\left(1000+\delta^{2} \mathrm{H}\right) / 6.420135
$$

The laboratory standards used for measurements were periodically calibrated against primary standards: VSMOW2, VSLAP2 (Vienna Standard Light Antarctic Precipitation 2) and GISP (Greenland Ice Sheet Precipitation), supplied by the International Atomic Energy Agency IAEA, Vienna (IAEA, 2007; IAEA 20017). Measurement reproducibility of duplicates was around $\pm 1 \%$.

\subsection{Tritium measurements}

All tritium measurements were performed by a low-background liquid scintillation spectrometer Quantulus $1220^{\mathrm{TM}}$ (PerkinElmer), using a low background liquid scintillation cocktail (Ultima Gold uLLT). Thus $8 \mathrm{~g}$ of water sample (purified water resulted from aqueous fraction of the wine) was mixed with $12 \mathrm{~g}$ of scintillation cocktail mentioned above in $20 \mathrm{ml}$ polyethylene vials. Background samples and tritium standards were simultaneously prepared for each batch. Counting efficiency was determined by internal standard method according to SR EN ISO 9698:2019 using as tritium standard tritiated water provided by PerkinElmer; reference standard NIST SRM 4947C with a certified tritium activity of $2632100 \pm 3.208 \% \mathrm{dpm} / \mathrm{g}$, reference date June 12, 2017. Tritium free water used as background was deuterium depleted water obtained in National R\&D Institute for Cryogenics and Isotopic Technologies - ICSI Ramnicu Valcea, Romania. Samples and backgrounds (tritium free water) were counted for 1000 min per sample with 
a counting efficiency around $24 \%$ at the best figure of merit. In the same experimental conditions, the background was around $0.75 \mathrm{cpm}$, following a minimum detectable activity of about 0.45 $\mathrm{Bq} \mathrm{1}^{-1}$, evaluated according to SR EN ISO 9698:2019 (ASRO, 2019).

\section{RESULTS AND DISCUSSION}

Starting from the initial impure aqueous fraction of the wine samples, colored and containing a lot of organic and inorganic impurities, and applying the purification methods described above, we obtained purified colorless samples, which could be measured to determine tritium activity concentration using LSC. Estimation of the purification methods was done using characterization parameters suggested by the ISO standard (ASRO, 2019), such as $\mathrm{pH}$ around 7 , and conductivity below $100 \mu \mathrm{S} / \mathrm{cm}$. In order to monitor the degree of removal of organic compounds from the sample to be purified, TOC content was determined. The experimental results characterization parameters, for the samples applying all the purification methods are showed in Table 1.

Table 1. Estimation of the effectiveness of purification methods for studied samples, using $\mathrm{pH}$, conductivity and TOC

\begin{tabular}{|c|c|c|c|c|}
\hline $\begin{array}{c}\text { Aqueous } \\
\text { fraction } \\
\text { sample }\end{array}$ & $\begin{array}{c}\text { Purification } \\
\text { method } \\
\text { applied } \\
\end{array}$ & $p H$ & $\begin{array}{c}\text { Conductivity } \\
\mu \mathrm{S} / \mathrm{cm}\end{array}$ & $\begin{array}{c}\text { TOC content } \\
m g / l\end{array}$ \\
\hline \multirow{5}{*}{$\begin{array}{c}\text { Red wine } \\
\text { VR }\end{array}$} & Initial & 3.26 & 3210 & - \\
\hline & M1 & 8.88 & 89 & 160 \\
\hline & M2 & 6.32 & 510 & 112 \\
\hline & M3 & 5.61 & 57 & 382 \\
\hline & M4 & 4.28 & 98 & 1680 \\
\hline \multirow{5}{*}{$\begin{array}{l}\text { White } \\
\text { wine } \\
\text { VA1 }\end{array}$} & Initial & 3.18 & 2780 & - \\
\hline & M1 & 8.11 & 77 & 590 \\
\hline & M2 & 6.55 & 417 & 324 \\
\hline & M3 & 5.52 & 44 & 1420 \\
\hline & M4 & 4.49 & 93 & 4870 \\
\hline \multirow{5}{*}{$\begin{array}{l}\text { White } \\
\text { wine } \\
\text { VA2 }\end{array}$} & Initial & 3.02 & 2680 & - \\
\hline & M1 & 8.74 & 81 & 380 \\
\hline & M2 & 6.82 & 381 & 184 \\
\hline & M3 & 5.77 & 39 & 907 \\
\hline & M4 & 4.38 & 79 & 3810 \\
\hline
\end{tabular}

Optimum values of $\mathrm{pH}$, for all wine samples, were obtained after applying purification method M2, optimum values for conductivity after applying M3, and the lowest TOC content after applying method M2. 
In conclusion, no purification method was particularly noteworthy in terms of wine aqueous phase purification.

Although some of the purification methods have given satisfactory results ( $\mathrm{pH}$ close to neutral, lower conductivity and TOC content), it cannot be said about any of them that it obtained the best characteristics in the purification terms. Overall, it could be concluded that the third method is the one useful for the purpose described above. However, it was necessary to investigate the process of isotopic fractionation that may occur during purification. For this purpose, deuterium analysis was performed. The obtained results are showed in Table 2.

Table 2. Estimation of the effectiveness of purification method applied, using deuterium concentration

\begin{tabular}{|c|c|c|c|}
\hline \multirow{2}{*}{$\begin{array}{c}\text { Purification } \\
\text { method applied }\end{array}$} & \multicolumn{3}{|c|}{ Deuterium concentration, ppm } \\
\cline { 2 - 4 } & Red wine VR & White wine VA1 & White wine VA2 \\
\hline M1 & $155.1 \pm 0.1$ & $156.0 \pm 0.1$ & $154.8 \pm 0.1$ \\
\hline M2 & $155.9 \pm 0.1$ & $157.1 \pm 0.1$ & $156.2 \pm 0.1$ \\
\hline M3 & $153.7 \pm 0.1$ & $156.6 \pm 0.1$ & $153.3 \pm 0.1$ \\
\hline M4 & $156.6 \pm 0.1$ & $158.5 \pm 0.1$ & $156.4 \pm 0.1$ \\
\hline
\end{tabular}

The isotopic fractionation was observed on applying the purification methods. The method using lyophilization without any treatment (M4) was chosen as reference and the closest values for deuterium isotopic concentration was the one obtained from applying the second method. The next step was tritium analysis using LSC, and the obtained results are showed in Table 3.

Table 3. Tritium activity concentration obtained in the aqueous phase of wine samples, after applying purification

\begin{tabular}{|c|c|c|c|}
\hline \multirow{2}{*}{$\begin{array}{c}\text { Purification } \\
\text { method applied }\end{array}$} & \multicolumn{3}{|c|}{ Tritium activity concentration, Bq/l } \\
\cline { 2 - 4 } & Red wine VR & White wine VA1 & White wine VA2 \\
\hline M1 & $1.37 \pm 0.27$ & $7.06 \pm 0.37$ & $2.81 \pm 0.32$ \\
\hline M2 & $1.64 \pm 0.28$ & $8.15 \pm 0.37$ & $2.89 \pm 0.33$ \\
\hline M3 & $1.80 \pm 0.28$ & $6.48 \pm 0.30$ & $2.40 \pm 0.31$ \\
\hline M4 & $1.63 \pm 0.28$ & $7.90 \pm 0.34$ & $2.92 \pm 0.33$ \\
\hline
\end{tabular}

Tritium activities measured for the 3 wines were different from method to method, these differences being confirmed also by the deuterium depletion observed after stable isotope analysis. For red wine VR and for white wine VA2, there were no significant differences, while for white wine VR1 the isotopic fractionation observed for deuterium is also reflected in tritium measurements. Another point of interest in this investigation is tritium activity concentrations of the studied wine samples. The tritium level in red wine VR and in one of the white wines (VA2) is very close to level in precipitation (Duliu et al., 2018), but the level in the first white wine VA1 is higher, although it is far from attention 
limit recommended for drinking water of $100 \mathrm{~Bq} / \mathrm{l}(98 / 83 / \mathrm{EC}, 1998)$. Due to the fact that the purified samples met the requirements of SR EN ISO 9698:2019, eliminating the possibility of interference with the scintillation cocktail, the higher level of tritium recorded in VA1 sample may originate in a higher level of tritium in precipitation and implicitly in the air that characterizes the place of origin.

\section{CONCLUSIONS}

The most reliable purification method used for wine aqueous fractions, according to the results obtained for $\mathrm{pH}$, and TOC is chemical treatment followed by lyophilization.

Comparing with standardized methods which implies only lyophilization of the samples, all the methods used for sample purification conducted to depleted ${ }^{2} \mathrm{H}$ isotopic concentration. The closest values were obtained using chemical treatment followed by lyophilisation. The highest isotopic fractionation was registered after purification using natural zeolite and lyophilisation.

The isotopic fractionation measured during the preparation sample step did not influence the tritium concentration values for red wine VR and white wine VA2. The method uncertainty, according to SR EN ISO 9698:2019, k=1,96, of around 15\% (usually met for environmental levels, Duliu et al., 2018) incorporates the isotopic fractionation phenomenon for tritium measurement.

Significant differences in measured tritium concentration observed for white wine VA1. Similar results were obtained for chemical treatment followed by lyophilisation and standard methods - lyophilization without any treatment. For the other two methods lower tritium concentration values were obtained, underlying the isotopic fractionation proved by the depletion of deuterium. The uncertainty around 5\% allowed the observation of this phenomenon.

Due to the above explained experimental results, the purification method involving chemical treatment followed by lyophilization was chosen as part of routine procedure for tritium measurement from wine for further use in our laboratory.

\section{Funding}

This paper was prepared in connection with the work done for monitoring program of Experimental Pilot Plant for Tritium and Deuterium Separation - PESTD, from National R\&D Institute for Cryogenics and Isotopic Technologies - ICSI Ramnicu Valcea, Romania

\section{Author Contributions}

Irina Vagner and Diana Costinel prepared the aqueous samples. Carmen Varlam analyzed/interpreted the data for tritium LSC measurements. Irina Vagner elaborated the manuscript with the help of Carmen Varlam. Diana Costinel performed deuterium concentration determination.

\section{Conflict of Interest Statement}

There is no conflict of interest on this article.

\section{REFERENCES}

ASRO - Romanian National Standardization Body, (2019). SR EN ISO 9698:2019. Calitatea apei. Tritiu. Metoda de încercare prin numărarea scintilațiilor în mediu lichid

Duliu, O.G., Varlam, C., Shnawaw, M.D. (2018).18 years of continuous observation of tritium and atmospheric precipitations in Ramnicu Valcea (Romania): A time series analysis, Journal of Environmental Radioactivity, 190-191, 105-110 
Cotarlea, M.I., Paunescu, N., Galeriu, D., Mocanu, N., Margineanu, R., Marin, G. (1998). Determination of tritium in wine and wine yeast samples, Romanian Journal of Physics, 43, 147

Council of European Union (1998). Council Directive 98/83/EC of 3 November 1998 on the quality of water intended for human consumption

Geyh, M.A., Schleicher, H. (1990). Absolute Age Determination. Physical and Chemical Dating Methods and Their Application, Springer, Berlin, Heidelberg, ISBN: 978-3-540-51276-9

Fischer, E., Muller, H., Rapp, A., Steffan, H. (1980). Tritium and ${ }^{14} \mathrm{C}$ Contents of Wines of Different Vintage from the Northern and Southern Hemisphere, Zeitschrift für LebensmittelUntersuchung und Forschung, 171, 269-271

Kimura, S., Miyamura, T., Maeda, S., Iwamoto, A., (1998). Development of a Method for Tritium Measurement in Ethylalcohol and Application to Individual Component of Sake, Japanese Journal of Toxicology and Environmental Health, 44(6), 428-441

Kozák, K., Biró, T., (1984). Reconstruction of environmental tritium levels from wine analysis. Health Physics, 46(1), 193-203

Krajcar-Bronic, I., Horvatincic, N., Obelic, B., (1998). Two Decades of Environmental Isotope Records in Croatia: Reconstruction of the Past and Prediction of Future Levels, Radiocarbon, 40 (1), 399-416

International Atomic Energy Agency - IAEA, (2007). Reference Sheet for Reference Material GISP (Greenland Ice Sheet Precipitation), available to https://nucleus.iaea.org/sites/ReferenceMaterials/ Pages/GISP.aspx

International Atomic Energy Agency - IAEA, (2017). Reference Sheet for International Measurement Standards - VSMOW2 (Vienna Standard Mean Ocean Water 2), SLAP2 (Standard Light Antarctic Precipitation 2), RS_VSMOW2_SLAP2_rev1/2017-07-11, available to https://nucleus.iaea.org/sites/ReferenceMaterials/Pages/VSMOW2.aspx

Lawrence Livermore National Laboratory - LLNL, (2016). UCRL-TR-50027-15 - Environmental Report 2015, available to https://saer.llnl.gov

Ota, M., Kwamena, N-O. A., Mihok, S., Korolevych, V. (2017). Role of soil-to-leaf tritium transfer in controlling leaf tritium dynamics: Comparison of experimental garden and tritium-transfer model results. Journal of Environmental Radioactivity, Vol. 178-179, https://doi.org/10.1016/j.jenvrad.2017.09.002

Roether, W., (1967). Estimating the tritiu input to groundwater from wine samples: groundwater and direct run-off contribution to central European surface waters" in IAEA Proceedings Series "Isotopes in Hydrology", Symposium held in Vienna, 14-18 November 1966, STI/PUB/141, 73-91

Schönhofer, F., (1997). Low-Level Measurements with Liquid Scintillation Spectrometry Development and Application in "Methods and Applications of Low-Level Radioactivity Measurements, Proceedings of Workshop Rossendorf/ Dresden, 7-8 November 1996”, Editor: J. Fietz

Takahashi, T., Nishida, M., Ohno, S., Hamada, T., (1969). Tritium Concentration in Wine, Rain and Ground Water, Radioisotopes, 18(12), 560-563

Varlam, C., Vagner, I., Faurescu, I., Faurescu, D. (2015). Combustion Water Purification Techniques Influence on OBT Analysis Using Liquid Scintillation Counting Method, Fusion Science and Technology, Vol. 67(3), 623-626, https://doi.org/10.13182/FST14-T95

This article is an open access article distributed under the terms and conditions of the Creative Commons Attribution (CC BY-NC-ND 4.0) license (https://creativecommons.org/licenses/by-nc-nd/4.0/). 